\title{
A SMART GRID WIRELESS NEURO-FUZZY POWER CONTROL FOR WIND ENERGY SYSTEMS
}

\author{
A. J. Sguarezi Filho*, C. E. Capovilla*, Ivan R. S. Casella*, R. V. Jacomini*, \\ J. L. A. Puma** and E. Ruppert** \\ CECS/UFABC - Santo André - SP - Brasil* DSCE/FEEC/UNICAMP**Campinas - SP - Brasil**
}

\{alfeu.sguarezi, carlos.capovilla, ivan.casella, \}@ufabc.edu.br, rogeriovj@yahoo.com.br, jl.azcue@gmail.com, ruppert@fee.unicamp.br

Abstract - The wind energy generation is the huge driver behind the push for supergrids and cross-border infrastructure for renewable energy systems. To improve the energy system and reduce deployment costs, the wireless communications can arise as a powerful tool in this new scenario. However, the wireless technology for transmitting control information to wind generator requires special attention to avoid any damage to the generator and to the energetic plant caused by transmission errors. In this context, this work proposes a wireless coded power control system for variable speed wind doubly-fed induction generators. The proposed controller is based on the adaptive neuro-fuzzy inference system and it uses the vector control technique to independently control the active and reactive power. The wireless communication system employs QPSK digital modulation and LDPC coding scheme to reduce the transmission errors and the overall system latency. In addition, it is presented its feasibility analysis and impact to the overall system by investigating the control performance in operational conditions at AWGN and flat fading propagation channels.

Keywords - DFIG, Wind energy, Smart grid, Neurofuzzy control, Wireless communication, LDPC

\section{INTRODUCTION}

A modern power generation controlling in smart grid requires a complex telecommunications system infrastructure to a fully efficient operation [1]. The smart grids are an evolution of the energy grid and are based on a more efficient employment of the infrastructure for generation, transmission, and distribution, in order to manage the relationship between power supply and demand in the electrical system to avoid contingencies [2]. For a optimized operation, the fully complete smart energy system needs a set with a strong interaction formed by communication networks, data management, and monitoring applications in real time [3].

Wireless technologies utilization for transmitting power control signals may cause apprehension, due to errors generated in the recovered control signal which can cause serious problems to the generators, and consequentially, to the energy system. Such behavior is different from what usually happens in telecommunications systems designed to conversation and data transmission, where small errors can be detected, initiate requests for retransmission (generating

Artigo submetido em 19/12/2011. Revisado em 17/08/2013. Aceito para publicação em 17/08/2013 por recomendação do editor João Onofre Pereira Pinto. delays) or even in some cases be ignored without any significant impact to the network.

Comparing and looking through a modern renewable energy system, the wind energy is the huge driver [4] and the DoublyFed Induction Generator (DFIG) is widely used with this purpose [5]. Wind energy systems using a DFIG have some advantages due to variable speed operation and four quadrant active and reactive power capabilities compared with fixed speed squirrel cage induction generators [6-8].

In this context, this paper proposes a wireless neuro-fuzzy power control system, to improve robustness and reliability, for a variable speed wind DFIG employing Low Density Parity Check (LDPC) coding [9] in smart grid applications.

The paper is organized as follows. DFIG neuro-fuzzy power control is shown in section II; the wireless coded communication is presented in section III; main results are considered in section IV; and section V concludes the work.

\section{DFIG NEURO-FUZZY POWER CONTROL}

\section{A. Machine model and rotor current vector control}

The doubly-fed induction generator model in synchronous $d q$ reference frame is given by [10]:

$$
\vec{v}_{1 d q}=R_{1} \vec{i}_{1 d q}+\frac{d \vec{\lambda}_{1 d q}}{d t}+j \omega_{1} \vec{\lambda}_{1 d q}
$$

$$
\vec{v}_{2 d q}=R_{2} \vec{i}_{2 d q}+\frac{d \vec{\lambda}_{2 d q}}{d t}+j\left(\omega_{1}-N_{P} \omega_{m e c}\right) \vec{\lambda}_{2 d q}
$$

and the relationships between fluxes and currents are:

$$
\begin{aligned}
& \vec{\lambda}_{1 d q}=L_{1} \vec{i}_{1 d q}+L_{M} \vec{i}_{2 d q} \\
& \vec{\lambda}_{2 d q}=L_{M} \vec{i}_{1 d q}+L_{2} \vec{i}_{2 d q}
\end{aligned}
$$

so, the active and reactive powers are given by:

$$
\begin{aligned}
& P=\frac{3}{2}\left(v_{1 d} i_{1 d}+v_{1 q} i_{1 q}\right) \\
& Q=\frac{3}{2}\left(v_{1 q} i_{1 d}-v_{1 d} i_{1 q}\right)
\end{aligned}
$$

The subscripts 1 and 2 represent the stator and rotor parameters, respectively; $\omega_{1}$ represents the synchronous speed, $\omega_{\text {mec }}$ represents machine speed, $R$ represents winding per phase electrical resistance, $L$ and $L_{M}$ represent the proper and the mutual inductances of windings, $\vec{v}$ represents voltage vector, $\vec{i}$ represents current vector, $\vec{\lambda}$ represents flux vector and $N_{P}$ represents the machine number of pair of poles. 
The DFIG power control aims independent stator active $P$ and reactive $Q$ power control by means of a rotor current regulation. For this purpose, $P$ and $Q$ are represented as functions of each individual rotor current. Using stator flux orientation, that decouples the $d q$ axis, it has that $\lambda_{1 d}=\lambda_{1}=$ $\left|\vec{\lambda}_{1 d q}\right|$, thus, the equation (3) becomes:

$$
\begin{gathered}
i_{1 d}=\frac{\lambda_{1}}{L_{1}}-\frac{L_{M}}{L_{1}} i_{2 d} \\
i_{1 q}=-\frac{L_{M}}{L_{1}} i_{2 q}
\end{gathered}
$$

Where $i_{1 d}$ is direct axis component and $i_{1 q}$ is quadrature axis component of the current vector in $d q$ axis.

Similarly, using stator flux oriented, the stator voltage becomes $v_{1 d}=0$ and $v_{1 q}=v_{1}=\left|\vec{v}_{1 d q}\right|$. Hence, the active (5) and reactive (6) power can be calculated by using equations (7) and (8):

$$
\begin{gathered}
P=-\frac{3}{2} v_{1} \frac{L_{M}}{L_{1}} i_{2 q} \\
Q=\frac{3}{2} v_{1}\left(\frac{\lambda_{1}}{L_{1}}-\frac{L_{M}}{L_{1}} i_{2 d}\right)
\end{gathered}
$$

Thus, rotor currents will reflect on stator current and on stator active and reactive powers, respectively. Consequently, this principle can be used on stator active and reactive power control of the DFIG.

\section{B. Neuro-Fuzzy System}

The Adaptive Neuro-Fuzzy Inference System (ANFIS), shown in Figure 1, is a network structure whose overall inputoutput behavior is determined by the values of a collection of modifiable parameters. More specifically, the configuration of an adaptive network is composed of a set of nodes connected through directed links, where each node is a process unit that performs a static node function on its incoming signals to generate a single node output and each link specifies the direction of signal flow from one node to another.

Usually, a node function is a parameterized function with modifiable parameters. By changing these parameters, we are actually changing the node function, as well as the overall behavior of the adaptive network [11].

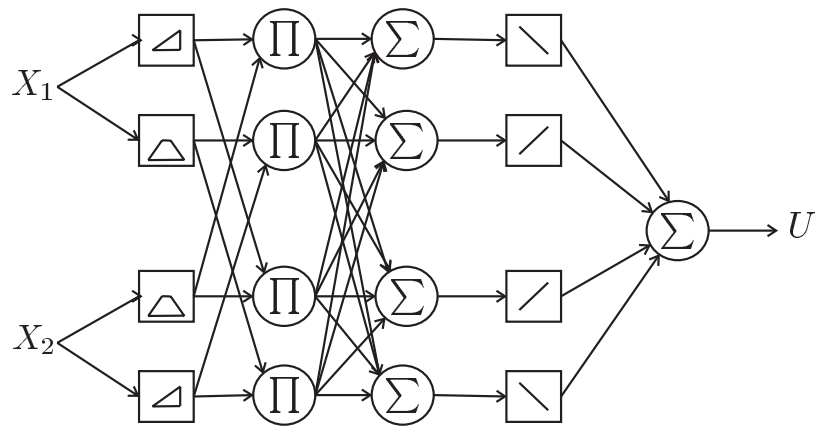

Fig. 1. ANFIS structure.

The parameters of an adaptive network are distributed into the network nodes, so each node has a local parameter set.
The union of these local parameter sets is the network overall parameter set. If a node parameter set is nonempty, then its node function depends on the parameter values; we use a square to represent this kind of adaptive node. On the other hand, if a node has an empty parameter set, then its function is fixed; we use a circle to denote this type of fixed node [11].

The ANFIS network uses two sets of parameters $S 1$ and $S 2$. The first one represents the fuzzy partitions used in the rules and the second one represents the coefficients of the linear functions in the rules.

$$
\begin{aligned}
S 1=\{ & \left\{a_{11}, b_{11}, c_{11}\right\},\left\{a_{12}, b_{12}, c_{12}\right\}, \ldots, \\
& \left.\left\{a_{1 p}, b_{1 p}, c_{1 p}\right\}, \ldots,\left\{a_{n p}, b_{n p}, c_{n p}\right\}\right\}
\end{aligned}
$$

$$
S 2=\left\{\left\{C_{10}, C_{11}, \ldots, C_{1 n}\right\}, \ldots,\left\{C_{P^{n} 0}, C_{P^{n} 1}, \ldots, C_{P^{n} n}\right\}\right\}
$$

The ANFIS uses a two-pass learning cycle, in the forward pass: $\mathrm{S} 1$ is fixed and S2 is computed using a Least Squares (LS) algorithm (Off-line Learning), and in the backward pass: $\mathrm{S} 2$ is fixed and $\mathrm{S} 1$ is computed using a Gradient Descent (GD) algorithm (usually Back-propagation [12]).

\section{Design of ANFIS Controllers}

The ANFIS controller $[11,13]$ was designed with the input and output data set collected from the DFIG operating at different conditions with the deadbeat controller [14].

In the Figure 2, it is shown graphically the substitution that was made, it should be mentioned that this is a simplified representation of the deadbeat controller with the purpose of illustrating that the ANFIS has the same function as the deadbeat controller. The proposed ANFIS controller has only the rotor current error as input different than presented in the literature [15]. The final neuro-fuzzy power control for DFIG is shown in Figure 3.
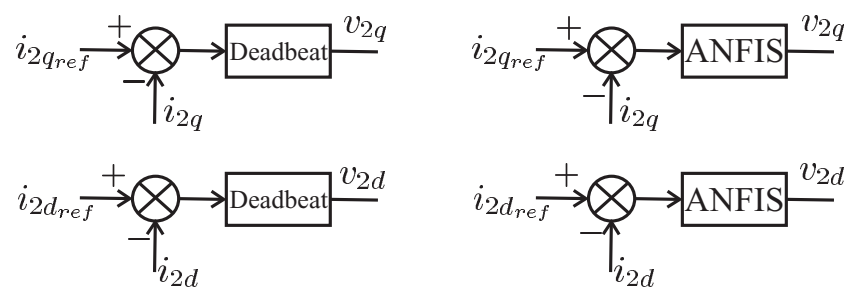

Fig. 2. ANFIS Controller.

The tests used in this work to collect data set training are similar to the ones used for Singh [15]:

- Operation at different wind speed profiles;

- Operation at different ramp increments in wind speed;

- Operation at different step increments in wind speed;

- Operation during voltage sag conditions. 


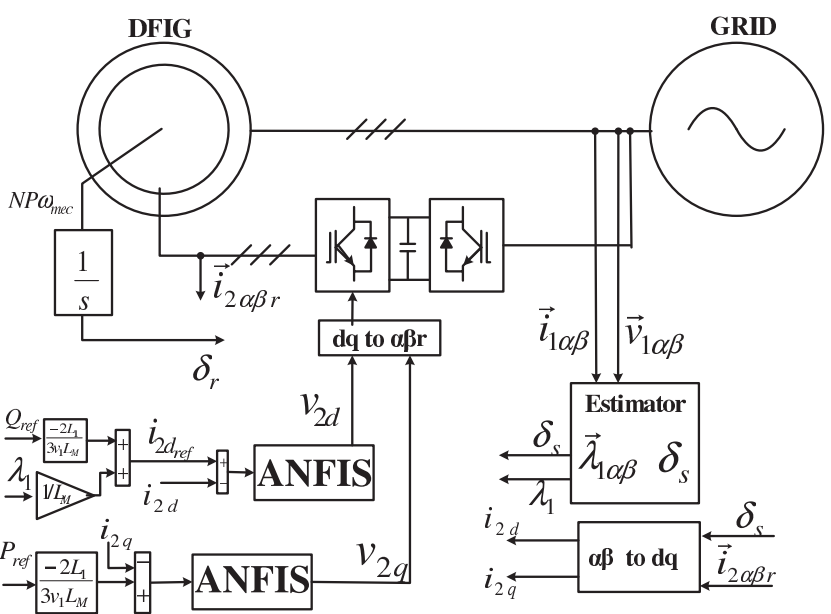

Fig. 3. Neuro-Fuzzy DFIG power control.

The grid partition method is chosen to design the fuzzy controller structure, which usually involves only several state variables as the inputs to the controller. For input and output, a generalized bell Membership Function (MF or bell MF) has been considered and the MF is specified by three parameters $a, b, c$, besides the input $x$ :

$$
\operatorname{bell}(x, a, b, c)=\frac{1}{1+\left|\frac{x-c}{a}\right|^{2 b}}
$$

where, the parameter $b$ is usually positive.

A desired generalized bell MF can be obtained by a proper selection of the parameter set $\{a, b, c\}$. Specifically, we can adjust $c$ and $a$ to vary, respectively, the center and width of the MF and then use $b$ to control the slopes at the crossover points [11].

The ANFIS structure was trained with the hybrid method, this one combines the least squared error algorithm and backpropagation method. The ANFIS was trained considering maximum 5000 epochs and an error tolerance of 0.0001 . To calculate the numerical value resulting from the activated rules, it was used the weighted average method for defuzzification.

Thus, if the $d$ and $q$ axis voltage components are calculated according to the ANFIS controller and are applied to the generator, then the active and reactive power convergence to their respective commanded values will occur in a few samplings intervals. The desired rotor voltage in the rotor reference frame $\left(\delta_{s}-\delta_{r}\right)$ generates switching signals for the rotor side using either space vector modulation.

\section{Estimation}

The stator flux $\vec{\lambda}_{1 \alpha \beta}$ estimation in stationary reference frame is given by:

$$
\vec{\lambda}_{1 \alpha \beta}=\int\left(\vec{v}_{1 \alpha \beta}-R_{1} \vec{i}_{1 \alpha \beta}\right) d t
$$

and the stator flux position by using equation (14) as:

$$
\delta_{s}=\arctan \left(\frac{\lambda_{1 \beta}}{\lambda_{1 \alpha}}\right)
$$

The angle between stator and rotor flux is given by:

$$
\delta_{s}-\delta_{r}=\int \omega_{s l} d t
$$

\section{WIRELESS CODED COMMUNICATION}

The proposed wireless control system, shown in Figure 4, uses LDPC codes $[9,16,17]$ to improve system performance and reliability. The LDPC are $\left(N_{c}, N_{b}\right)$ binary linear block codes that have a sparse parity-check matrix $\mathbf{H}$ that can be described in terms of a Tanner graph [18], where each bit in the codeword corresponds to a variable node and each paritycheck equation corresponds to a check node. A check node $j$ is connected to a variable node $k$ whenever the element $h_{j, k}$ in $\mathbf{H}$ is equal to $1[16,18]$.

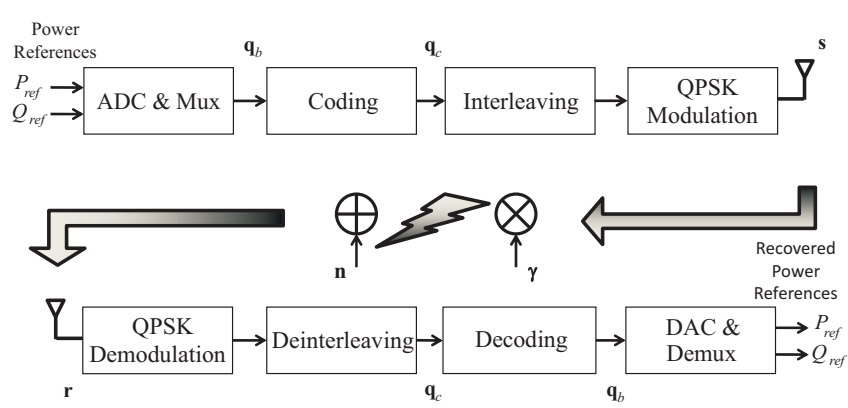

Fig. 4. Wireless Coded Communication Diagram.

Extended Irregular Repeat Accumulate (eIRA) codes [1923] are a special subclass of LDPC codes that improve the systematic encoding process and generate good irregular LDPC codes for high code rate applications. The eIRA paritycheck matrix can be represented by $\mathbf{H}=\left[\begin{array}{ll}\mathbf{H}_{1} & \mathbf{H}_{2}\end{array}\right]$, where $\mathbf{H}_{1}$ is a sparse $\left(N_{m}\right)$ by $\left(N_{c}\right)$ matrix, that can be constructed irregularly by density evolution according to optimal weight distribution [22], and $\mathbf{H}_{2}$ is the $\left(N_{m}\right)$ by $\left(N_{m}\right)$ dual-diagonal square matrix given by:

$$
\mathbf{H}_{2}=\left[\begin{array}{lllll}
1 & & & & \\
1 & 1 & & & \\
& 1 & \ddots & & \\
& & \ddots & 1 & \\
& & & 1 & 1
\end{array}\right]
$$

where $N_{b}$ is the number of control bits, $N_{c}$ is the number of coded bits and $N_{m}$ is the number of parity bits.

Given the constraint imposed on the $\mathbf{H}$ matrix, the generator matrix can be represented in the systematic form by the $\left(N_{b}\right)$ by $\left(N_{C}\right)$ matrix:

$$
\mathbf{G}=\left[\begin{array}{ll}
\mathbf{I} & \boldsymbol{\Psi}
\end{array}\right]
$$

where $\mathbf{I}$ is the identity matrix, $\boldsymbol{\Psi}=\mathbf{H}_{1}^{\mathrm{T}} \times \mathbf{H}_{2}^{-\mathrm{T}}$ and $\mathbf{H}_{2}^{-\mathrm{T}}$ is the upper triangular matrix given by: 


$$
\mathbf{H}_{2}^{-\mathrm{T}}=\left[\begin{array}{cccccc}
1 & 1 & 1 & \cdots & 1 & 1 \\
& 1 & 1 & \cdots & 1 & 1 \\
& & 1 & & 1 & 1 \\
& & & \ddots & \vdots & \vdots \\
& & & & 1 & 1 \\
& & & & & 1
\end{array}\right]
$$

The encoding process can be accomplished by first multiplying the control information vector $\mathbf{q}_{b}=\left[\begin{array}{lll}q_{b}(1) & \cdots & q_{b}\left(N_{b}\right)\end{array}\right]^{T}$ by the sparse matrix $\mathbf{H}_{1}^{\mathrm{T}}$ and then differentially encoding this partial result to obtain the parity bits. The systematic codeword vector $\mathbf{q}_{c}=\left[\begin{array}{lll}q_{c}(1) & \cdots & q_{c}\left(N_{c}\right)\end{array}\right]^{T}$ can be simply obtained by combining the control information and the parity bits.

In the transmission process, the codeword vector is then interleaved and Quaternary Phase Shift Keying (QPSK) mapped using Gray code [24], resulting in the symbol vector $\mathbf{s}=\left[\begin{array}{lll}s(1) & \cdots & s\left(N_{s}\right)\end{array}\right]^{T}$, where $N_{s}$ is the number of transmitted coded control symbols. Afterward, the coded symbols are filtered, upconverted and transmitted by the wireless fading channel.

Assuming that the channel variations are slow enough that intersymbol interferences (ISI) can be neglect, the fading channel can be modeled as a sequence of zero-mean complex Gaussian random variables with autocorrelation function [24, 25]:

$$
R_{h}(\tau)=J_{0}\left(2 \pi f_{D} T_{s}\right)
$$

where $J_{0}()$ is the zero-th order Bessel function, $T_{s}$ is the signaling time and $f_{D}$ is the Doppler spread.

Thus, in the receive process, the complex low-pass equivalent discrete-time received signal can be represented by [24]:

$$
\mathbf{r}=\gamma \cdot \mathbf{s}+\mathbf{n}
$$

where $\mathbf{r}=\left[\begin{array}{lll}r(1) & \cdots & r\left(N_{s}\right)\end{array}\right]^{T}$ is the received signal vector, $\gamma=\left[\begin{array}{llll}\gamma(1) & \cdots & \gamma\left(N_{s}\right)\end{array}\right]^{T}$ is the vector of complex coefficients of the channel and $\mathbf{n}=\left[\begin{array}{lll}n(1) & \cdots & n\left(N_{s}\right)\end{array}\right]^{T}$ is the Additive White Gaussian Noise (AWGN) vector. Note that the above vector multiplication is performed element by element.

Once the transmitted vector $\mathbf{s}$ is estimated, considering perfect channel estimation, the transmitted control bits can be recovered by performing symbol demapping, code deinterleaving and bit decoding.

Decoding can be accomplished by a message passing algorithm [26-29] based on the Maximum A Posteriori (MAP) criterion [16], that exchanges soft-information iteratively between the variable and check nodes. The exchanged messages can be represented by the following Log-Likelihood Ratio (LLR):

$$
L_{c_{k}}=\log \left[\frac{p\left(\mathbf{q}_{c}(k)=0 \mid \mathbf{d}\right)}{p\left(\mathbf{q}_{c}(k)=1 \mid \mathbf{d}\right)}\right]
$$

where $p\left(\mathbf{q}_{c}(k)\right.$ is the probability of the codeword vector $\mathbf{q} \mathbf{c}$ to be equal to 0 or 1 .
The LLR message from the $j^{t h}$ check node to the $k^{t h}$ variable node is given by:

$$
L_{r_{j, k}}=2 \operatorname{atanh}\left[\prod_{k^{\prime} \in V_{j \backslash k}} \tanh \left(\frac{L_{q_{k^{\prime}, j}}}{2}\right)\right]
$$

The set $V_{j}$ contains the variable nodes connected to the $j^{\text {th }}$ check node and the set $C_{k}$ contains the check nodes connected to the $k^{t h}$ variable node. $V_{j \backslash k}$ is the set $V_{j}$ without the $k^{t h}$ element, and $C_{k \backslash j}$ is the set $C_{k}$ without the $j^{t h}$ element. The LLR message from the $k^{\text {th }}$ variable node to the $j^{\text {th }}$ check node is obtained by:

$$
L_{q_{k, j}}=L_{c_{k}}+\sum_{j^{\prime} \in c_{k \backslash j}} L_{r_{j^{\prime}, k}}
$$

and the LLR for the $k^{t h}$ code bit is given by:

$$
L_{Q_{k}}=L_{c_{k}}+\sum_{j \in c_{k}} L_{r_{j, k}}
$$

At the end of each iteration, $L_{Q_{k}}$ provides an updated estimate of the a posteriori LLR of the transmitted coded bit $q_{c}(k)$. If $L_{Q_{k}}>0$, then $q_{c}(k)=1$, else $q_{c}(k)=0$.

\section{CONTROL SYSTEM PERFORMANCE}

The proposed wireless control for the DFIG connected to the grid was simulated in the MATLAB-Simulink using the SimPowerSystems, Fuzzy logic, and Communications toolboxes. The system has a sampling time of $0.5 \times 10^{-4} \mathrm{~s}$ and the DFIG parameters are shown in the Appendix. The active and reactive power references were step changed, respectively, from -100 to $-120 \mathrm{~kW}$ and from 60 to $0 \mathrm{kVAR}$ at $1.25 \mathrm{~s}$. At $1.5 \mathrm{~s}$, the references also were step changed from -120 to -60 $\mathrm{kW}$ and from 0 to $-40 \mathrm{kVAR}$. Again, at $1.75 \mathrm{~s}$, the references were step changed from -60 to $-100 \mathrm{~kW}$ and from -40 to -60 $\mathrm{kVAR}$. These references are the inputs of the wireless coded power control, shown in Figure 4, which is analyzed for two different scenarios: an AWGN channel and a more realistic flat fading correlated Rayleigh channel.

The system is evaluated for a frequency flat fading Rayleigh channel with a Doppler spread of $180 \mathrm{~Hz}$. The LDPC coding scheme uses the $(64,800$ and 32,400$)$ eIRA code specified in [30] and an ordinary Convolution Coding (CC) scheme with a $(171,133)$ generator polynomial with constrain length of 7 is used as reference of performance [16]. Both schemes have code rate of $1 / 2$ and employ a random interleaving of length 64,800 . For simplicity, the number of iterations in the LDPC decoding is limited to 25 . The bit duration is $1.25 \times 10^{-5}$ $\mathrm{s}$ and each transmitted frame is composed by 32,400 QPSK coded symbols.

In Figures 5 and 6, the final responses of the wireless power control system employing CC are presented for an $E_{b} / N_{0}$ of $10 \mathrm{~dB}$. The spikes presented in the responses of the system occur due to the errors in the wireless communication, even with the use of a very efficient error correction scheme. 

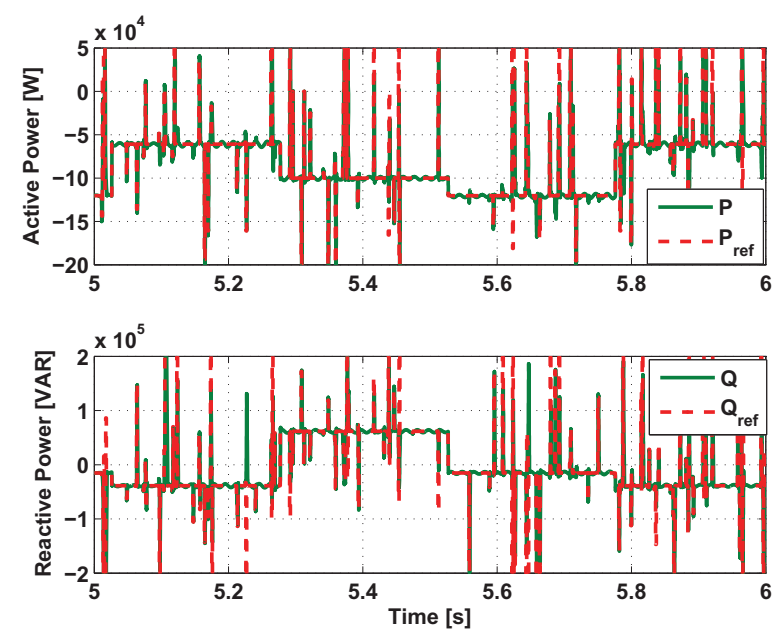

Fig. 5. Step Response of Active and Reactive Powers Using CC Coding in a Flat Fading Channel.
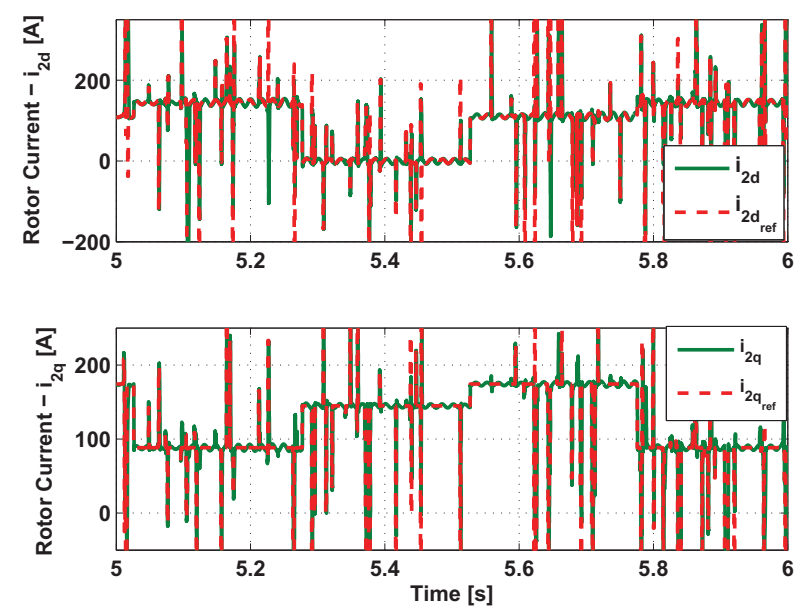

Fig. 6. Step Response of Rotor Current $\vec{i}_{2_{d q}}$ Using CC Coding in a Flat Fading Channel.

It can be observed that several of these spikes, presented in the reference signals, are followed by the controller and not others due to the fact that the time response of the controller is not sufficient to follow quick changes caused by destructive effects of the channel in the transmitted signal. In this way, the problem would be aggravated in a controller with faster time response.

These errors in the control system can permanently damage the aerogenerator, the wind generation, or even, cause a loss of system efficiency, since the machine will not generate its maximum power track at that moment, and additionally, they generate undesirable harmonic components to the power grid. The damage related to wind generation occurs due to the fact that high values of $\frac{d i}{d t}$, as shown in Figure 7 , can completely deteriorate the Insulated Gate Bipolar Transistors (IGBTs) and, consequently, through the power converter, it can cause short circuits in rotor and/or stator of the generator.
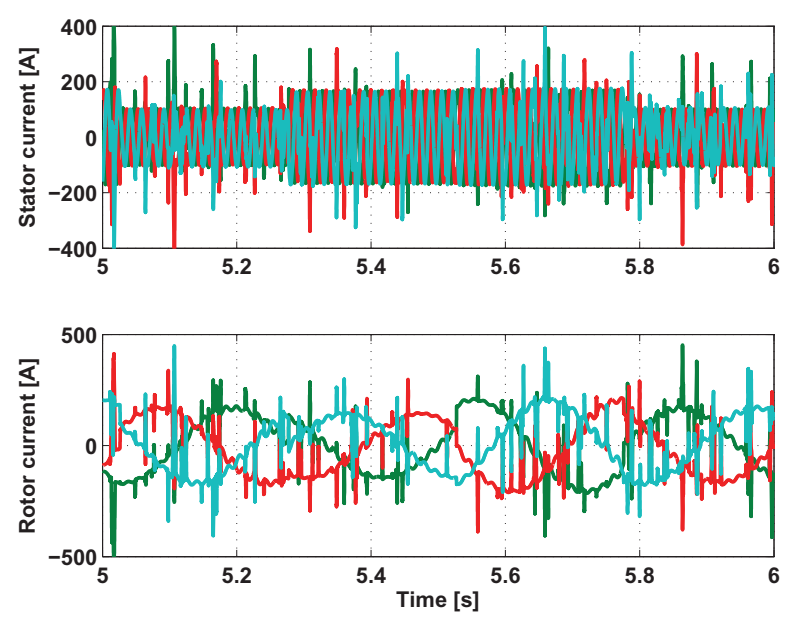

Fig. 7. Stator and Rotor Currents Using CC Coding in a Flat Fading Channel.

Thus, it is necessary to use a wireless control system capable of minimizing the occurrence of these spikes arising from errors caused by the channel distortions. With this finality, it is highlighted the proposal of using a more robust wireless control system based on LDPC coding. Figures 8 and 9 show the response of the wireless controller employing the LDPC coding scheme for an $E_{b} / N_{0}$ of $10 \mathrm{~dB}$ and the same step reference signals described at the beginning of this section.
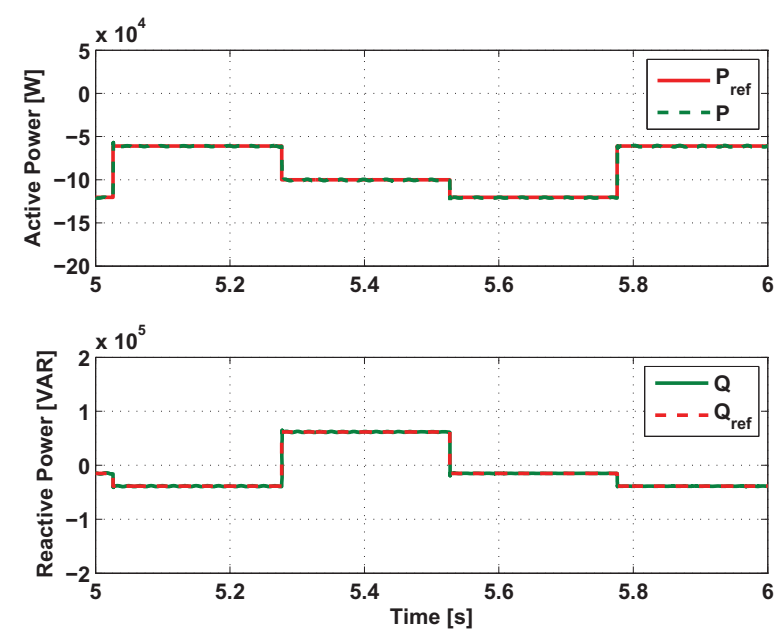

Fig. 8. Step Response of Active and Reactive Powers Using LDPC Coding in a Flat Fading Channel.

The satisfactory performance of the wireless control system can be seen due to the fact the references were perfectly followed by the controller and the inexistence of destructive spikes caused by errors in the wireless transmission system. Additionally, these good functionalities are shown in Figure 10, where the stator currents present expected 
waveforms. It is important to emphasize that the errors generated in the wireless transmission are independent of the power control technique and they cannot be easily removed without using advanced FEC coding technique as the LDPC employed in this work.
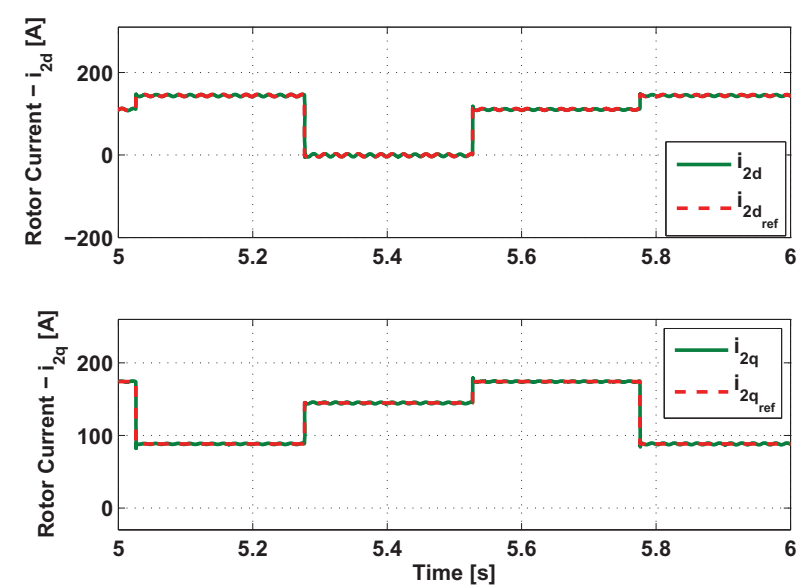

Fig. 9. Step Response of Rotor Current $\vec{i}_{2_{d q}}$ Using LDPC Coding in a Flat Fading Channel.

To complete the analysis, it is evaluated the performance of the proposed wireless coded neuro-fuzzy power control system for different values of $E_{b} / N_{0}$ and different propagation scenarios to show its robustness and functionality.
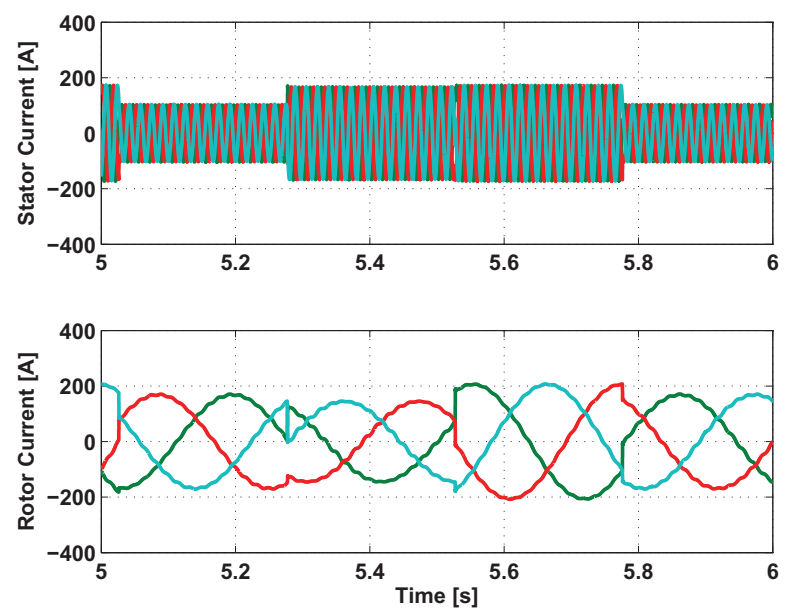

Fig. 10. Stator and Rotor Currents Using LDPC Coding in a Flat Fading Channel.

In Figures 11 and 12 comparisons of performance for No Coding, CC, and LDPC schemes are presented. As expected, the performance of LDPC is significantly superior than CC for both propagation scenarios. As pointed out in Figure 11, the performance improvement of LDPC over CC in AWGN channels for a BER of $10^{-5}$ is approximately $5.3 \mathrm{~dB}$ while, as shown in Figure 12 for flat fading channels, the improvement is approximately $26.8 \mathrm{~dB}$ for the same BER (Bit Error Rate).

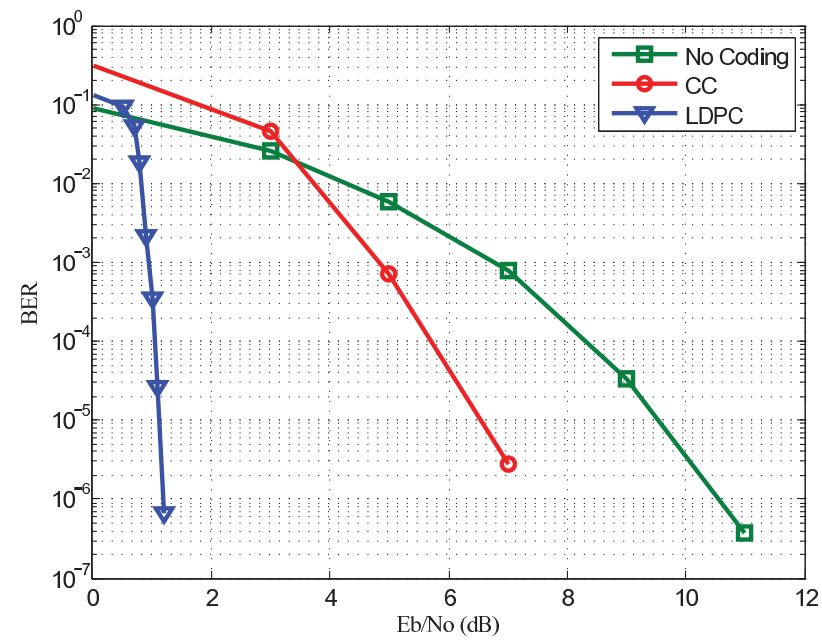

Fig. 11. Performance Comparison for Different Coding Schemes in AWGN Channel.

Tables I and II show the number and percentage of phase inversions, correspondent to $P_{r e f}$ and $Q_{r e f}$ references, presented in the recovered control signal for both scenarios. It can be seen that LDPC coding requires a significant lower $E_{b} / N_{0}$ to present the same order of phase inversions as CC. For a low BER as $10^{-5}$, there are some changes in the active and reactive power references that can cause serious problems in the generator, and consequentially, in the energy plant.

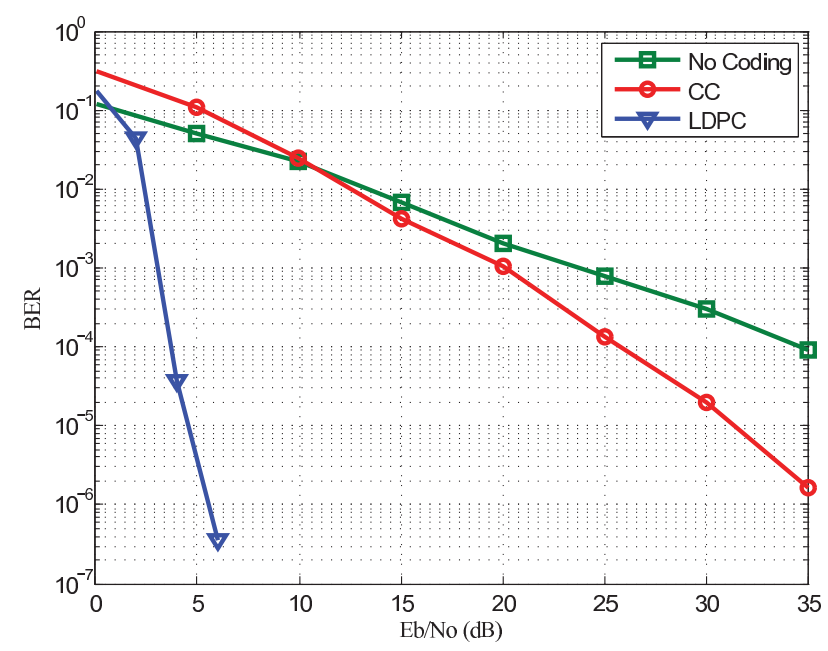

Fig. 12. Performance Comparison for Different Coding Schemes in Flat Fading Channel (180 Hz - QPSK).

However, the use of LDPC coding can reduce notably this number for a typical $E_{b} / N_{0}$ in real systems and can improve considerably system robustness to the channel impairments. For example, a system operating with a typical $E_{b} / N_{0}$ of 10 $\mathrm{dB}$ employing $\mathrm{CC}$ will fail dramatically, while a system using LDPC coding will be free of errors. 
TABLE I

Control Inversion in an AWGN Channel.

\begin{tabular}{cccc}
\hline $\begin{array}{c}\text { Coding } \\
\text { Scheme }\end{array}$ & $\begin{array}{c}\text { Bit Error } \\
\text { Rate }\end{array}$ & $\begin{array}{c}\text { Eb/No } \\
(\mathbf{d B})\end{array}$ & $\begin{array}{c}\text { Number of } \\
\text { Inversions }\end{array}$ \\
\hline CC & $10^{-3}$ & 4.80 & $225(0.12 \%)$ \\
CC & $10^{-4}$ & 5.65 & $21(0.01 \%)$ \\
CC & $10^{-5}$ & 6.40 & $2(0.001 \%)$ \\
LDPC & $10^{-3}$ & 0.98 & $204(0.11 \%)$ \\
LDPC & $10^{-4}$ & 1.06 & $21(0.01 \%)$ \\
LDPC & $10^{-5}$ & 1.13 & $2(0.001 \%)$ \\
\hline
\end{tabular}

TABLE II

Control Inversion in a Flat Fading Channel.

\begin{tabular}{cccc}
\hline $\begin{array}{c}\text { Coding } \\
\text { Scheme }\end{array}$ & $\begin{array}{c}\text { Bit Error } \\
\text { Rate }\end{array}$ & $\begin{array}{c}\text { Eb/No } \\
(\mathbf{d B})\end{array}$ & $\begin{array}{c}\text { Number of } \\
\text { Inversions }\end{array}$ \\
\hline CC & $10^{-3}$ & 20.0 & $167(0.087 \%)$ \\
CC & $10^{-4}$ & 25.5 & $21(0.01 \%)$ \\
CC & $10^{-5}$ & 31.5 & $4(0.002 \%)$ \\
LDPC & $10^{-3}$ & 3.20 & $188(0.098 \%)$ \\
LDPC & $10^{-4}$ & 3.80 & $26(0.013 \%)$ \\
LDPC & $10^{-5}$ & 4.70 & $1(0.0005 \%)$ \\
\hline
\end{tabular}

\section{CONCLUSION}

In this paper, it was proposed a wireless coded control system using a neuro-fuzzy controller applied to a doublyfed induction aerogenerator. An analysis for different coding schemes shows that, even for a relatively low BER, the power reference changes can occur and it can be very dangerous for the generator and the energy plant.

However, the use of LDPC coding improves significantly the robustness of the system in severe noise and fading channel situations, eliminating the occurrence of errors in the active and reactive power references for operational conditions.

\section{ACKNOWLEDGEMENT}

The authors are grateful to FAPESP for the financial support for this research.

\section{Appendix}

Doubly-fed induction generator parameters [31]: $R_{1}=24.75 \mathrm{~m} \Omega ; R_{2}=13.3 \mathrm{~m} \Omega ; L_{M}=14.25 \mathrm{mH}$; $L_{l 1}=284 \mu \mathrm{H} ; L_{l 2}=284 \mu \mathrm{H} ; J=2.6 \mathrm{Kg} \cdot \mathrm{m}^{2} ; N_{P}=2$; $P_{N}=149.2 \mathrm{kVA}$ and $V_{N}=575 \mathrm{~V}$

\section{REFERENCES}

[1] R. Strzelecki and G. Benysek, Power Electronics in Smart Electrical Energy Networks. Springer-Verlag, 2008.

[2] M. D. Ilic, "From hierarchical to open access electric power systems," Proceedings of the IEEE, vol. 95, no. 5, pp. 1060-1084, May 2007.

[3] F. Li, W. Qiao, H. Sun, H. Wan, J. Wang, Y. Xia, Z. Xu, and P. Zhang, "Smart transmission grid: Vision and frameworks," IEEE Transactions on Smart Grid, vol. 1, no. 2, pp. 186-192, September 2010.

[4] A. Keyhani, M. N. Marwali, and M. Dai, Integration of Green and Renewable Energy in Electric Power Systems, 2010.
[5] J. F. Manwell, J. G. McGowan, and A. L. Rogers, Wind Energy Explained: Theory, Design and Application, 2nd ed., 2010.

[6] M. G. Simoes and F. A. Farret, Renewable Energy Systems with Induction Generators. CRC Press, 2004.

[7] R. G. de Almeida and J. A. P. Lopes, "Participation of doubly fed induction wind generators in system frequency regulation," IEEE Transactions on Power Systems, vol. 22, no. 3, pp. 944-950, August 2007.

[8] R. Datta and V. T. Rangathan, "Variable-speed wind power generation using doubly fed wound rotor induction machine - A comparison with alternative schemes," IEEE Transation on Energy Conversion, vol. 17, no. 3, pp. 414421, September 2002.

[9] R. G. Gallager, Low-Density Parity-Check Codes. Cambridge, 1963.

[10] W. Leonhard, Control of Electrical Drives. SpringerVerlag Berlin Heidelberg New York Tokyo, 1985.

[11] J.-S. Jang and C.-T. Sun, "Neuro-fuzzy modeling and control," Proceedings of the IEEE, vol. 83, no. 3, pp. 378-406, Mar. 1995.

[12] S. Haykin, Neural Networks: A Comprehensive Foundation, 2nd ed. Prentice Hall, 1998.

[13] J.-S. Jang, "ANFIS: adaptive-network-based fuzzy inference system," IEEE Transactions on Systems, Man, and Cybernetics, vol. 23, no. 3, pp. 665-685, 1993.

[14] A. J. S. Filho and E. Ruppert, "A deadbeat active and reactive power control for doubly-fed induction generators," Electric Power Components and Systems, vol. 38, no. 5, pp. 592-602, 2010.

[15] B. Singh, E. Kyriakides, and S. N. Singh, "Intelligent control of grid connected unified doubly-fed induction generator," in IEEE Power and Energy Society General Meeting, 2010, pp. $1-7$.

[16] S. Lin and D. J. Costello, Error control coding. Prentice Hall, 2004.

[17] Y. Zhang and W. E. Ryan, "Toward low LDPCcode floors: a case stud," IEEE Transactions on Communications, vol. 57, no. 6, pp. 1566-1573, June 2009.

[18] R. M. Tanner, "A recursive approach to low complexity codes," IEEE Transactions on Information Theory, vol. 27, no. 5, pp. 533-547, September 1981.

[19] H. Jin, A. Khandekar, and R. J. McEliece, "Irregular repeat-accumulate codes," Proc. Int. Symp. Turbo Codes and Related Topics, pp. 1-5, September 2000.

[20] M. Yang and W. E. Ryan, "Lowering the error-rate floors of moderate length high-rate irregular LDPC codes," Int. Symp. Information Theory, vol. 2, p. 237, July 2003.

[21] M. Yang, W. E. Ryan, and Y. Li, "Design of efficiently encodable moderate-length high-rate irregular LDPC codes," IEEE Transactions on Communications, vol. 52, no. 4, pp. 564-571, April 2004.

[22] Y. Zhang, W. E. Ryan, and Y. Li, "Structured eIRA codes with low floors," Proceedings of the International Symposium on Information Theory, pp. 174-178, September 2005.

[23] J. Kim, A. Ramamoorthy, and S. Mclaughlin, "The 
design of efficiently-encodable rate-compatible ldpc codes," IEEE Transactions on Communications, vol. 57, pp. 365-375, 2009.

[24] J. G. Proakis and M. Salehi, Digital Communications. McGraw-Hill, 2008.

[25] A. Barbieri, A. Piemontese, and G. Colavolpe, "On the arma approximation for frequency-flat rayleigh fading channels," IEEE International Symposium on Information Theory, pp. 1211-1215, June 2007.

[26] T. Richardson, A. Shokrollahi, and R. Urbanke, "Design of capacity-approaching low-density paritycheck codes," IEEE Transactions on Information Theory, vol. 47, pp. 619-637, February 2001.

[27] T. Richardson and R. Urbanke, "The capacity of low-density parity check codes under message-passing decoding," IEEE Transactions on Information Theory, vol. 47, pp. 599-618, February 2001.

[28] L. Dinoi, F. Sottile, and S. Benedetto, "Design of versatile eIRA codes for parallel decoders," IEEE Transactions on Communications, vol. 56, no. 12, pp. 2060-2070, 2008.

[29] B. Shuval and I. Sason, "On the universality of LDPC code ensembles under belief propagation and $\mathrm{ml}$ decoding," IEEE 26th Convention of Electrical and Electronics Engineers, pp. 355-359, 2010.

[30] ETSI, "Dvb-s.2," Standard Specification, pp. 302-307, March 2005.

[31] A. J. S. Filho, M. E. de Oliveira Filho, and E. Ruppert, "A predictive power control for wind energy," IEEE Transactions on Sustainable Energy, vol. 2, no. 1, pp. 97 105, January 2011.

\section{BIOGRAPHIES}

Alfeu J. Sguarezi Filho was born in Cuiabá-MT, Brazil, in 1981. He received his bachelor degree in Electrical Engineering from Faculdade Área 1, his M.S. and his Ph.D. degrees from Campinas University in Brazil, respectively in 2005, 2007 and 2010. He was working as researcher at Campinas University by FAPESP pos-doctoral program from 2010 to 2011. Now, he is a professor at Federal University of $\mathrm{ABC}$ - UFABC, teaching in the areas of Electrical Machines, Power Electronics and Electrical Drives. His research interests are machine drives, doubly-fed induction generators, power control and electrical power systems.

Carlos Eduardo Capovilla was born in Vinhedo, Brazil, on March 06, 1977. He received the B.S. degree from the University of Sao Paulo in 2001, M.Sc. and Ph.D. degrees from the Universidade Estadual de Campinas in 2004 and 2008, all in Electrical Engineering - Microelectronics. $\mathrm{He}$ is currently a Professor with the Universidade Federal do ABC. His current research interests include RF CMOS integrated circuits, smart antennas, mobile systems design, smart grid applications and telecommunications in complex environments.

Ivan R. S. Casella received his B.S. in Electrical Engineering from the Mackenzie University and his M.S. and $\mathrm{PhD}$. in Electrical Engineering from the Polytechnic School of the University of Sao Paulo (EPUSP). Part of his
PhD was developed at the University of Toronto (UofT) in Canada, where he acted as research assistant and teacher assistant. He also worked as electronic designer at the Consumer Electronics Development Laboratories of Philips and as researcher at the Automation and Informatics Research and Development Center of NEC (CPDIA), both in Brazil, in the analysis and development of analog and digital systems. Additionally, he coordinated the Radio Frequency Switching Group in the project of the set-top-box reference design for the Brazilian Digital TV (SBTVD) at the Integrated Systems Laboratory (LSI) of EPUSP.

He is now Adjunct Professor III at the Federal University of $\mathrm{ABC}$ (UFABC) and chair of the Communication and Information Laboratory (LIC). His currently interests are in the areas of smart grid, wireless communication, resource allocation and evolutionary optimization.

Rogério Vani Jacomini was born in Santa Barbara DOeste, Sao Paulo, Brazil, in 1979. Received the B.S. degree in electrical engineering from Salesian University Center of São Paulo, Brazil, in 2004, the M.S. and Ph.D. degree from State University of Campinas, Brazil, in 2008 and 2012, respectively. Currently, he is working toward as researcher at UFABC, Brazil. His current research interest include AC drives and and doubly fed induction machine.

José Luis Azcue Puma was born in Peru in 1981. He received his college education at Universidad Nacional del Altiplano in Peru, and received his bachelor degree in Electronics Engineering in 2004. He received his M.S. and Ph. D. degrees in Electrical Engineering in 2010 and 2013, respectively, from University of Campinas (UNICAMP) in Brazil. His primary areas of interest are electrical machines, ac drives, power electronics, intelligent electrical drives, fuzzy controllers and fuzzy systems. Mr. Azcue is student member of IEEE and member of Industrial Electronics Society of IEEE.

Ernesto Ruppert Filho received his bachelor degree in Electrical Engineering and his Master and $\mathrm{PhD}$ degrees from Campinas University in Brazil, respectively in 1971, 1974 and 1983. From 1972 to 1978 he had been working at Electrical and Computer Enginneering School of Campinas University as an Assistance Professor in the Electromechanical Energy Conversion area, from 1979 to 1983 he had been working for General Electric in Brazil designing large induction and synchronous motors and working as an Application Engineer dedicated to large motors and generators, from 1983 to 1989 he had been working for Vigesa Heavy Equipments in Brazil designig very large hydrogenerators and also performing commissionig testes in some hydro power plants in Brazil. From 1989 to 1992 he runned his own company dealing with electrical installations and from 1992 up to now he is working as Full Professor at the Electrical and Computer Engineering School of Campinas University, in Campinas, Brazil, researching and teaching in the areas of Electrical Machines, Power Electronics, Drives and Electrical Power Systems. 